\title{
The impact of lymph node count on survival in gastric cancer
}

\author{
Ha Rim Ahn, Se Wung Han, Doo Hyun Yang, Chan Young Kim \\ Division of Gastrointestinal Surgery, Department of Surgery, Chonbuk National University College of Medicine, Jeonju, Korea
}

Purpose: The purpose of this study was to determine the immunologic role of lymph node (LN) and stage migration by assessing LN count and metastatic LN count.

Methods: A total of 2,117 patients with gastric adenocarcinoma located in the body and antrum who underwent distal/subtotal gastrectomy with D2 LN dissection between January 1, 1998 and December 31, 2008 were enrolled. LN count and number of metastases were determined in the N1 tier (area of D1 dissection) and N2 tier (area of D2 dissection). The lower and upper quartiles of LN counts in the same pN stage were grouped to compare the prognosis and LN positivity according to the LN tier.

Results: Stage migration from N1 tier to N2 tier occurred in 3.2\% of cases. The 5-year disease-specific survival rates of the upper and lower $\mathrm{LN}$ count groups within the $\mathrm{N} 1$ tier were $91.0 \%$ and $86.7 \%(\mathrm{P}=0.01)$, respectively. $\mathrm{LN}$ positivity in the N2 tier of the lower $\mathrm{LN}$ count group was higher than that of the upper $\mathrm{LN}$ count group ( $14.1 \%$ vs. 8.2\%, $\mathrm{P}<0.01)$. Stage migration in the $\mathrm{N} 2$ tier of the lower $\mathrm{LN}$ count group was also higher than that of the upper $\mathrm{LN}$ count group ( $4.6 \%$ vs. 1.8\%, $\mathrm{P}<0.01)$.

Conclusion: The lower $L N$ count group had a decreased survival rate compared to that of the upper $L N$ count group, suggesting that perigastric LN has an immunological defense role in weakening the disseminating power of metastatic tumor cells, as indicated by the LN count.

Keywords: Stomach neoplasm, Lymph node, Stage migration

\section{INTRODUCTION}

The Union for International Cancer Control/American Joint Committee on Cancer (UICC/AJCC) classifies the N stage of gastric cancer based on the metastatic lymph node (LN) count [1,2]. N stage is important for determining treatment strategies and predicting prognosis along with tumor depth (pT stage), and harvesting more than $15 \mathrm{LNs}$ is recommended for proper $\mathrm{N}$ staging. Inappropriate $\mathrm{LN}$ count results in an inappropriate node-negative result, leading to a lower overall stage, referred to as stage migration. Stage migra-

Received: Aug 24, 2018 Revised: Oct 25, 2018 Accepted: Nov 12, 2018 Correspondence to: Chan Young Kim

Department of Surgery, Chonbuk National University College of Medicine, 20 Geonji-ro, Deokjin-gu, Jeonju 54907, Korea

Tel: +82-63-250-2298, Fax: +82-63-271-6197

E-mail: happyhill98@gmail.com

ORCID: Ha Rim Ahn (https://orcid.org/0000-0002-5187-3712), Se Wung Han, (https://orcid.org/0000-0001-7252-3976), Chan Young Kim (https://orcid. org/0000-0001-6656-9425)

Copyright (C) 2018 Korean Society of Surgical Oncology

This is an Open Access article distributed under the terms of the Creative Commons Attribution Non-Commercial License (http://creativecommons.org/licenses/by-nc/4.0) which permits unrestricted non-commercial use, distribution, and reproduction in any medium, provided the original work is properly cited. tion shows a worse survival than that of appropriately assessed LN count. However, a large LN count shows better prognosis, suggesting the prognostic significance of the LN count. Most of surgeons agree on the extent of LN dissection, which minimizes stage migration, in order to compare prognosis. Experienced surgeons not only perform LN dissection but also perform LN harvest for pathological examination. In Korea and Japan, D2 LN dissection is the standard LN dissection guideline for gastric cancer, and gastric surgeries are performed by experienced surgeons at hospitals specializing in gastric cancer surgery. There is a tendency to perform LN harvest during surgery, minimizing the possibility of missing positive LNs.

Recently, suspicions have been raised that stage migration is exaggerated in meta-analysis studies, arguing that although there is evidence that fat clearance and methylene blue staining during LN harvest increases LN count [2], there is no evidence that this increases LN positivity and upstaging [3]. Some studies also reported that $\mathrm{LN}$ count is an indicator for host immunologic role against tumor dissemination [4]. However, there is no direct evidence, and more studies need to be conducted.

The purpose of this study was to determine the immunologic role of LN and stage migration by assessing LN count and metastatic LN count. 


\section{METHODS}

Among 3,041 patients, 2,841 received radical distal/subtotal gastrectomy with D2 LN dissection between January 1, 1998 and December 31, 2008. Patients with cancer located in the upper third, who received neoadjuvant chemotherapy, and who previously underwent surgery for other intra-abdomen cancer or gastric cancer surgery were excluded from this study. Finally, the remaining 2,117 patients were included in the present study.

The hospital in which the surgeries were performed is a center that specializes in gastric cancer surgery and in which more than 150 surgeries are performed annually. Two specialized surgeons (DHY and CYK) performed the surgeries in the present study. Depending on the location of the primary tumor, one-half or twothirds of the stomach was eliminated, and en bloc was performed for LN dissection of D2 or higher. Then, the surgeon divided the soft tissue based on LN station at the operation field and placed LN based on LN station into formalin. These samples were then sent for pathological examination.

The $\mathrm{pN}$ stage was performed according to the UICC/AJCC TNM classifications 7th edition. Japanese Gastric Cancer Association recommendations were followed for each LN station, D1 and D2, for $\mathrm{LN}$ dissection. LN stations 1, 3, 4sb, 4d, 5, 6, 7 were included in the D1 area, while both the D1 area and LN stations 8a, 9, $11 \mathrm{p}$, and $12 \mathrm{a}$ were included in the D2 area. First, the pN stage was determined based on metastatic LN count in the $\mathrm{D} 1$ area. LN positivity changes in LN 8a, 9, 11p, and 12a areas were observed, and finally, changes in stage migration in the D2 area were recorded. The disease-specific five-year survival rate in $\mathrm{pN}$ stage within the

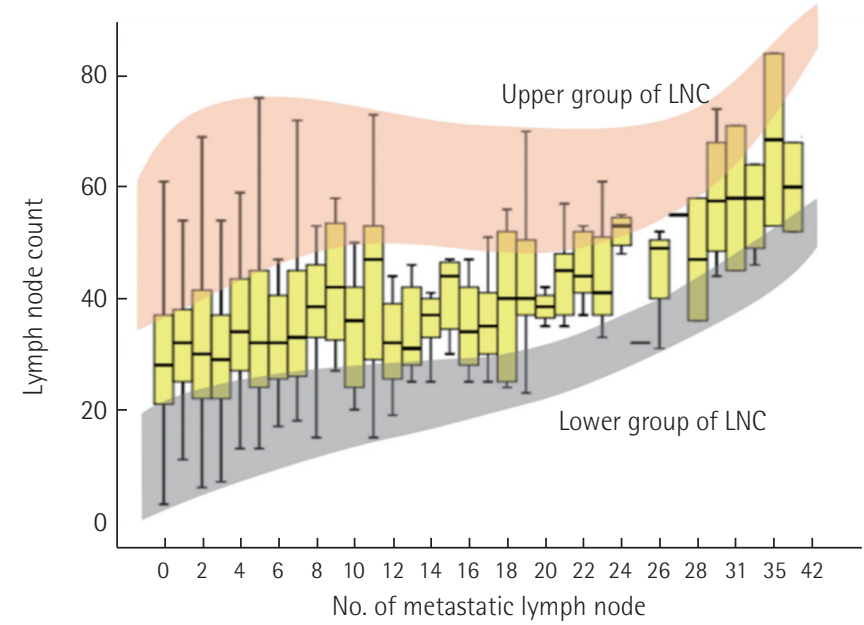

D1 area was also calculated in order to study the relationship between $\mathrm{LN}$ positivity and stage migration.

LN counts were divided into lower and upper groups according to quartile. Because $\mathrm{LN}$ count was in proportion to metastatic $\mathrm{LN}$ count, as shown in Fig. 1A, when LN count was divided into quartiles, more metastatic LN counts were included in the upper quartile, causing a selection error, $\mathrm{LN}$ count that was applied to the number of metastatic LN was divided into lower LN count group ( $<25$ percentile) and upper LN count group ( $>75$ percentile).

Differences in LN positivity and stage migration were observed between the lower and upper LN count groups. In order to compare disease-specific 5-year survival rates in the D1 and D2 areas, the lower and upper LN counts were calculated for both areas. The lower and upper LN count groups in D1 area included 570 and 575 patients, respectively. The lower and upper LN count groups in D2 area included 566 and 570 patients, respectively. Differences in clinicopathologic features were assessed between the lower and upper LN count groups for patient age, sex, body mass index (BMI), tumor size, extent of lymphadenectomy, tumor differentiation, Lauren classification, presence of lymphatic invasion, $\mathrm{pT}$ stage, $\mathrm{pN}$ stage, and TNM stage.

In patients with multiple synchronous gastric cancers, the lesion with the deepest infiltration of the gastric wall was regarded as the main lesion. The clinicopathological characteristics of the main lesion were used for the analysis. Resections were deemed radical when no gross residual disease was evident at the time of operation, with tumor-free resection margins on histological examination.

Not all patients were administered postoperative chemotherapy. Patients with advanced gastric cancer more than TNM stage II

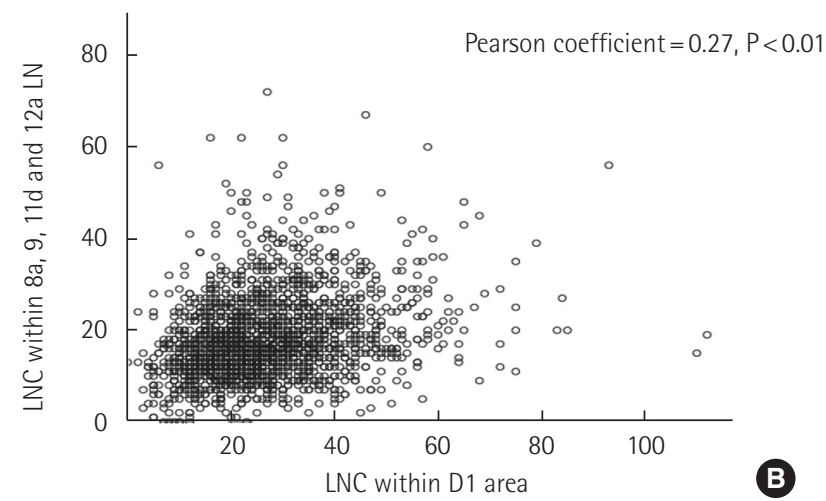

Fig. 1. Lymph node counts (LNCS) were divided into lower and upper groups according to quartile. (A) LNC increased in proportion to metastatic LNC (Pearson coefficient $=0.30, P<0.01$ ). In order to eliminate selection error, we marked the upper and lower LNC group through making a quartile for each number of the metastatic lymph node (LN). (B) LNCs within the LN 8a, 9, 11p, and 12a were proportionate with LNC within the D1 area, having a Pearson coefficient of $0.27(\mathrm{P}<0.01)$. 
were administered 5 -fluorouracil-based postoperative chemotherapy starting within three weeks after surgery. No patients were administered postoperative or preoperative radiotherapy.

In general, the follow-up consisted of abdominopelvic computed tomogram every 6 months for 5 years after surgery and esophag- gastro-duodenoscopy annually for 5 years after surgery. Follow-up of patients was completed until the cutoff date of 31 December, 2013. The median follow-up interval at the cutoff date was 50 months (range, 0-232 months). At the time of the last follow-up, 334 patients (11.8\%) had been lost to follow-up.

Table 1. Clinicopathologic characteristic of the lower and upper quartile group of lymph node count in the D1 and D2 dissection area

\begin{tabular}{|c|c|c|c|c|c|c|}
\hline \multirow{2}{*}{ Characteristic } & \multicolumn{3}{|c|}{ LNC quartile of D1 dissection area } & \multicolumn{3}{|c|}{ LNC quartile of D2 dissection area } \\
\hline & Lower $(n=570)$ & Upper $(n=575)$ & P-value & Lower $(n=566)$ & Upper $(n=570)$ & P-value \\
\hline $\begin{array}{l}\text { Sex } \\
\text { Male } \\
\text { Female }\end{array}$ & $\begin{array}{l}396(69.5) \\
174(30.5)\end{array}$ & $\begin{array}{l}380(66.1) \\
195(33.9)\end{array}$ & 0.23 & $\begin{array}{l}393(69.4) \\
173(30.6)\end{array}$ & $\begin{array}{l}398(69.8) \\
172(30.2)\end{array}$ & 0.89 \\
\hline $\begin{array}{l}\text { Age (yr) } \\
\quad<60 \\
\geq 60\end{array}$ & $\begin{array}{l}256(44.9) \\
314(55.1)\end{array}$ & $\begin{array}{l}324(56.3) \\
251(43.7)\end{array}$ & $<0.01$ & $\begin{array}{l}262(46.3) \\
304(53.7)\end{array}$ & $\begin{array}{l}322(56.5) \\
248(43.5)\end{array}$ & 0.01 \\
\hline $\begin{array}{l}\text { BMl }\left(\mathrm{kg} / \mathrm{m}^{2}\right) \\
\quad<20 \\
20-25 \\
>25\end{array}$ & $\begin{array}{r}73(12.8) \\
289(50.7) \\
208(36.5)\end{array}$ & $\begin{array}{r}122(21.3) \\
297(58.0) \\
110(20.7)\end{array}$ & $<0.01$ & $\begin{array}{r}66(11.7) \\
279(49.4) \\
220(38.9)\end{array}$ & $\begin{array}{l}133(23.4) \\
335(58.9) \\
101(17.7)\end{array}$ & $<0.01$ \\
\hline $\begin{array}{l}\text { Tumor size }(\mathrm{cm}) \\
\quad \leq 3 \\
>3\end{array}$ & $\begin{array}{l}348(61.7) \\
216(38.3)\end{array}$ & $\begin{array}{l}315(55.7) \\
251(44.3)\end{array}$ & 0.04 & $\begin{array}{l}353(62.9) \\
208(37.1)\end{array}$ & $\begin{array}{l}287(51.2) \\
274(48.8)\end{array}$ & $<0.01$ \\
\hline $\begin{array}{l}\text { Extent of lymphadenectomy } \\
\text { D2 } \\
\text { Over D2 }\end{array}$ & $\begin{array}{l}184(32.3) \\
386(67.7)\end{array}$ & $\begin{array}{l}189(32.9) \\
386(67.1)\end{array}$ & 0.85 & $\begin{array}{l}229(40.5) \\
337(59.5)\end{array}$ & $\begin{array}{l}157(27.5) \\
413(72.5)\end{array}$ & $<0.01$ \\
\hline $\begin{array}{l}\text { Differentiated } \\
\text { Well } \\
\text { Poorly }\end{array}$ & $\begin{array}{l}325(57.0) \\
245(43.0)\end{array}$ & $\begin{array}{l}287(49.9) \\
288(50.1)\end{array}$ & 0.01 & $\begin{array}{l}330(58.3) \\
236(41.7)\end{array}$ & $\begin{array}{l}295(51.8) \\
275(48.2)\end{array}$ & 0.01 \\
\hline $\begin{array}{l}\text { Lauren } \\
\text { Intestinal } \\
\text { Diffuse }\end{array}$ & $\begin{array}{l}265(60.0) \\
177(40.0)\end{array}$ & $\begin{array}{l}228(52.2) \\
209(47.8)\end{array}$ & 0.02 & $\begin{array}{l}276(61.6) \\
172(38.4)\end{array}$ & $\begin{array}{l}227(54.8) \\
187(45.2)\end{array}$ & 0.04 \\
\hline $\begin{array}{l}\text { Lymphatic invasion } \\
\text { Negative } \\
\text { Positive }\end{array}$ & $\begin{array}{l}287(69.2) \\
128(30.8)\end{array}$ & $\begin{array}{r}327(73.6) \\
117(26.4)\end{array}$ & 0.15 & $\begin{array}{l}286(67.5) \\
138(32.5)\end{array}$ & $\begin{array}{l}293(70.9) \\
120(29.1)\end{array}$ & 0.29 \\
\hline $\begin{array}{l}\text { pT stage } \\
\text { pT1 } \\
\text { pT2 } \\
\text { pT3 } \\
\text { pT4 }\end{array}$ & $\begin{array}{r}352(61.8) \\
67(11.8) \\
65(11.4) \\
86(15.0)\end{array}$ & $\begin{array}{r}326(56.7) \\
72(12.5) \\
72(12.5) \\
92(16.0)\end{array}$ & 0.44 & $\begin{array}{r}356(64.5) \\
65(11.5) \\
59(10.4) \\
77(13.6)\end{array}$ & $\begin{array}{r}301(52.8) \\
82(14.4) \\
70(12.3) \\
117(20.5)\end{array}$ & 0.01 \\
\hline $\begin{array}{l}\text { pN stage }{ }^{a)} \\
\text { pN0 } \\
\text { pN1 } \\
\text { pN2 } \\
\text { pN3a } \\
\text { pN3b }\end{array}$ & $\begin{array}{c}382(67.0) \\
63(11.1) \\
49(8.6) \\
35(6.1) \\
41(7.2)\end{array}$ & $\begin{array}{c}395(68.7) \\
59(10.3) \\
56(9.7) \\
36(6.3) \\
29(5.0)\end{array}$ & 0.58 & $\begin{array}{c}384(67.8) \\
63(11.1) \\
49(8.7) \\
34(6.0) \\
36(6.4)\end{array}$ & $\begin{array}{r}378(66.3) \\
57(10.0) \\
65(11.4) \\
39(6.8) \\
31(5.4)\end{array}$ & 0.51 \\
\hline $\begin{array}{l}\text { TNM stage }{ }^{a)} \\
\text { la } \\
\text { lb } \\
\text { Ila } \\
\text { Ilb } \\
\text { IIla } \\
\text { IIlb } \\
\text { IIlc }\end{array}$ & $\begin{array}{c}313(54.9) \\
58(10.2) \\
38(6.7) \\
46(8.1) \\
37(6.5) \\
39(6.8) \\
39(6.8)\end{array}$ & $\begin{array}{c}300(52.2) \\
62(10.8) \\
45(7.8) \\
51(8.9) \\
29(5.0) \\
43(7.5) \\
45(7.8)\end{array}$ & 0.83 & $\begin{array}{c}323(57.1) \\
56(9.9) \\
39(6.9) \\
44(7.8) \\
34(6.0) \\
33(5.8) \\
37(6.5)\end{array}$ & $\begin{array}{c}277(48.6) \\
62(10.9) \\
49(8.6) \\
55(9.6) \\
33(5.8) \\
40(7.0) \\
54(9.5)\end{array}$ & 0.12 \\
\hline
\end{tabular}

Values are presented as number (\%).

LNC, lymph node count; BMI, body mass index.

a)Final stage including D2 and over D2 lymph node dissection patients. 
All statistical analyses were performed using SPSS 15.0 (SPSS, Inc., Chicago, IL, USA). Categorical variables were compared by chi-square tests. Correlation analysis was performed with twotailed test, and Pearson coefficients were calculated. Disease-specific survival rates were determined using the Kaplan-Meier method and compared using log-rank tests. For all analyses, P-values of $<0.05$ were considered statistically significant.

All information was obtained with appropriate Institutional Review Board waivers, and data were collected without revealing any personal information. The study was approved by the Ethical Review Board at the Chonbuk National University, Jeonju, Korea (2012-01-003).

\section{RESULTS}

The mean age of patients was 59 years (median, 60; standard deviation [SD], 11.3; range, 22-91 years), with a male-to-female ratio of 2.1:1. The clinicopathologic characteristics of the lower and upper LN count groups in the D1 and D2 areas are shown in Table 1. The characteristics that showed differences between the lower and upper groups for the D1 area included age, BMI, tumor size, adenocarcinoma differentiation, and Lauren classification, while the extent of lymphadenectomy and pT stage differed in the D2 area.

There were 677 patients with D2 LN dissection (32.5\%), and 1,430 patients were diagnosed with over D2 LN dissection (67.5\%). The TNM stage for the patient group was as follows: Ia, 1,465 (55.2\%); Ib, 221 (10.4\%); IIa, 161 (7.6\%); IIb, 178 (8.4\%); IIIa, 109 (5.1\%); IIIb, 141 (6.7\%); and IIIc, 139 (6.6\%). The median LN count for the total patient group was 45 (mean, 48.0; SD, 20.2; range,

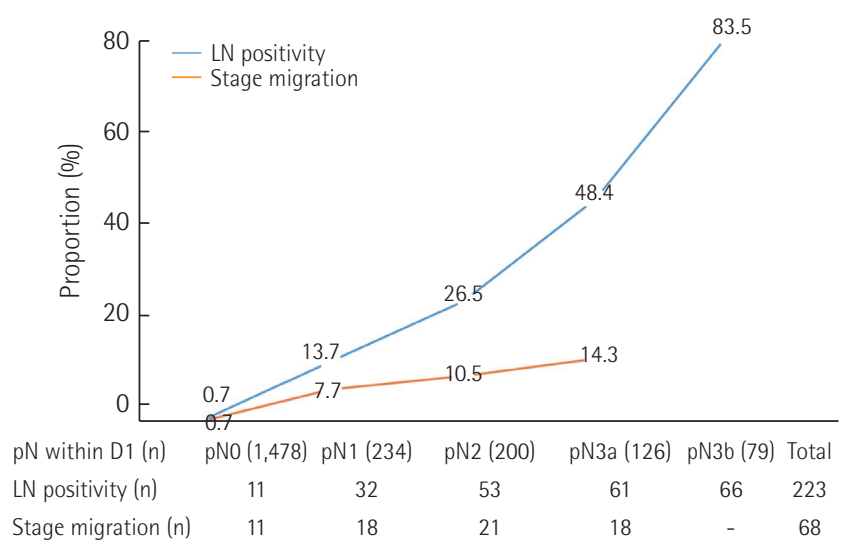

Fig. 2. The pN stage and stage migration. Subdividing according to $\mathrm{pN}$ stage within the $\mathrm{D} 1$ area shows the ratio between the lymph node (LN) positivity in the $L N 8 a, 9,11 p, 12 a$ area and the $p N$ stage within the D1 area shows the frequency of stage migration in the $\mathrm{D} 2$ area. LN positivity and stage migration increased with $\mathrm{pN}$ stage.
6-168). The median LN count for the D1 area was 25 (mean, 26.6; SD, 12.6; range, 2-112). The median for the LN 8a, 9, 11p, and 12a areas were 17 (mean, 18.2; SD, 8.9; range, 0-72). The median LN count for the D2 area was 42 (mean, 44.8; SD, 17.4; range, 6-149). Fig. $1 \mathrm{~A}$ is a graph of the total metastatic and total $\mathrm{LN}$ counts, which are proportionate $(\mathrm{P}<0.01)$. Fig. $1 \mathrm{~B}$ shows that the $\mathrm{LN}$ count of $\mathrm{D} 1$ area and the $\mathrm{LN} 8 \mathrm{a}, 9,11 \mathrm{p}$, and 12a areas were also proportionate.

The median positive LN count in the D1 area was 4.0 (mean, 5.8; SD, 7.5; range, $1-43$ ) and 639 patients (30.2\%) showed LN positivity. The median positive LN count for the LN 8a, 9, 11p, and 12a areas was 2.0 (mean, 2.9; SD, 4.4; range, 1-33), with 223 patients (10.5\%) showing LN positivity. Two hundred and twelve patients showed LN positivity in both areas. Only 11 patients $(0.5 \%)$ showed negative results in the $\mathrm{D} 1$ area but positive in the $\mathrm{D} 2$ area. The median positive $\mathrm{LN}$ count in the $\mathrm{D} 2$ area was 4.0 (mean, 6.7; SD, 9.7; range, 1-73) and 650 patients (30.7\%) showed LN positivity in the LN 8a, 9, 11p, and 12a area, which included 11 patients with $\mathrm{LN}$ positivity.

Sixty-eight patients (3.2\%) showed stage migration between the D1 and D2 areas. Subdividing according to $\mathrm{pN}$ stage within the D1 area in order to observe the changes in LN positivity and stage migration in the $\mathrm{LN} 8 \mathrm{a}, 9,11 \mathrm{p}$, and 12a areas revealed LN positivity and stage migration of $0.7 \%$ and $0.7 \%$, respectively, for $\mathrm{pN} 0$; $13.7 \%$ and $7.7 \%$, respectively, for $\mathrm{pN} 1 ; 26.5 \%$ and $10.5 \%$, respectively, for pN2; $48.4 \%$ and $14.3 \%$, respectively, for pN3a; $\mathrm{pN} 3 \mathrm{~b}$ had an $\mathrm{LN}$ positivity of $83.5 \%$, showing an increase with increased $\mathrm{pN}$ stage (Fig. 2).

One minus the cumulative 10-year disease-specific survival rates for $\mathrm{pN}$ stage within the $\mathrm{D} 1$ area were $0.8 \%, 15.8 \%, 17.3 \%$, $46.7 \%$, and $81.0 \%$ for $\mathrm{pN} 0, \mathrm{pN} 1, \mathrm{pN} 2, \mathrm{pN} 3 \mathrm{a}$, and $\mathrm{pN} 3 \mathrm{~b}$, respectively, which were similar to the LN positivity rates of $0.7 \%, 13.7 \%$, $26.5 \%, 48.4 \%$, and $83.5 \%$ for $\mathrm{pN} 0$, pN1, pN2, pN3a, and pN3b, re-

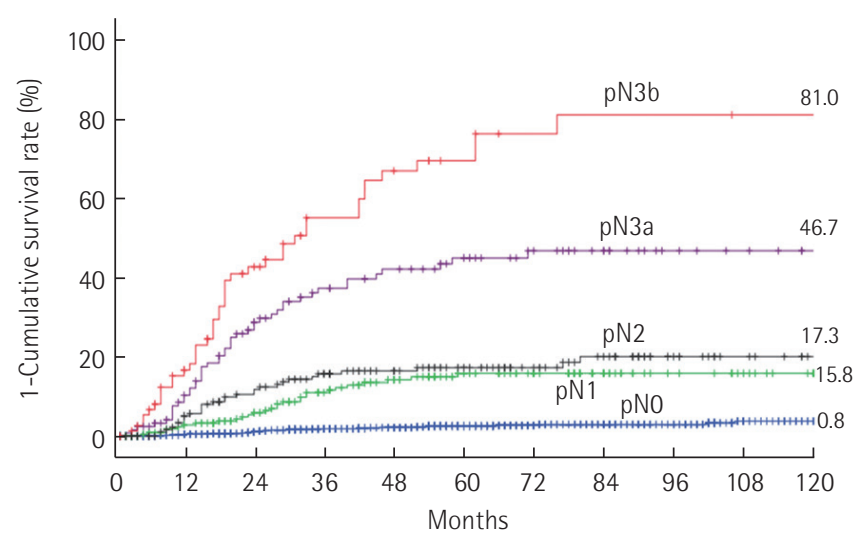

Fig. 3. The 10-year disease-specific survival rate for $\mathrm{pN}$ stage within D1 are 1- the cumulative 10-year disease-specific survival rate similar to the lymph node (LN) positivity rate in LN 8a, 9, 11p, 12a area. 

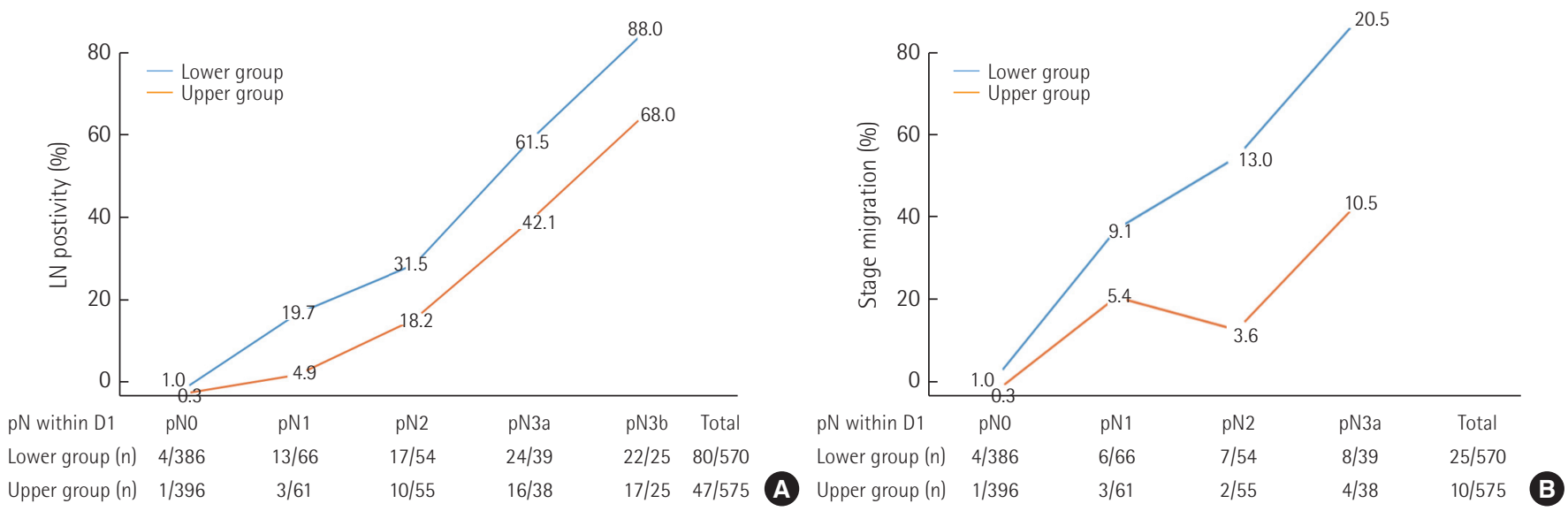

Fig. 4. The lymph node (LN) positivity and stage migration. (A) The ratio of $L N$ positivity within $L N 8 a, 9,11 p, 12 a$ area is shown through $p N$ stage within the D1 area. While LN positivity increases with pN stage, there was more in the lower group of lymph node count (LNC) than the upper group $(\mathrm{P}=0.01)$. (B) $\mathrm{pN}$ stage within the $\mathrm{D} 1$ area shows the frequency of stage migration in the $\mathrm{D} 2$ area. While the stage migration increases with $\mathrm{pN}$ stage, there was a higher frequency in group of $\mathrm{LNC}(\mathrm{P}=0.01)$.

spectively (Fig. 3).

Analysis of the differences in LN positivity within the LN 8a, 9, $11 \mathrm{p}$, and 12a areas in the lower and upper LN count groups within the $\mathrm{D} 1$ area revealed that the total positivity rate in the lower group was $14.0 \%$ compared to $8.2 \%$ in the upper group and was also higher for each $\mathrm{pN}$ stage $(\mathrm{P}=0.01)$ (Fig. $4 \mathrm{~A})$. The rates of stage migration in the lower and upper LN count groups were $4.4 \%$ and $1.7 \%$, respectively, with a significantly higher stage migration in the lower $\mathrm{LN}$ count group $(\mathrm{P}=0.01)$ (Fig. 4B).

The disease-specific five-year survival rates in the lower and upper $\mathrm{LN}$ count groups for the D1 area were $86.7 \%$ and $91.0 \%$, respectively $(\mathrm{P}=0.01)$ (Fig. 5). The rates for the $\mathrm{D} 2$ area were $88.5 \%$ and $91.5 \%$, respectively $(\mathrm{P}=0.04)$. The survival rate for the lower $\mathrm{LN}$ count group was low for each $\mathrm{pN}$ stage from $\mathrm{pN} 1$ to $\mathrm{pN} 3 \mathrm{a}$, with the exception of $\mathrm{pN} 0$.

\section{DISCUSSION}

The important initial event by which solid tumors spread occurs through the lymphatic system. Since metastatic regional LN is considered a prognostic indicator, it is important to avoid missing positive LNs. To obtain sufficient $\mathrm{LN}$ count is not only by the range of $\mathrm{LN}$ dissection but the motivation of the pathologist as well. While the national guidelines suggest harvesting more than 15 LNs, up to three times this number is required to approach the Japanese standard. Therefore, there is an increased risk for stage migration with inappropriate LN dissection or when the pathologist is passive at finding LNs [5-8]. However, some authors argue that stage migration could be over-exaggerated. In a multicenter randomized trial, Degiuli et al. [9] reported that the LN positivity rates for $\mathrm{D} 1$ and $\mathrm{D} 2$ dissection (51.5\% and 55.2\%, respectively), as well as the range of $\mathrm{pN}$ stage, did not differ significantly. In another study comparing D2 and D1 dissection, the mean LN counts were 37.2 and 19.2, respectively, but the node positivity rates did not differ significantly, at $3.9 \%$ and $3.4 \%$, respectively. Our results were similar to these previous findings. The median LN count of the D1 and D2 areas were 25 and 42 , respectively, but the median number of positive LNs was the same (4.0) and the LN positivity rates were $30.2 \%$ and $30.7 \%$, respectively. While patients with stage migration showed an increasing pattern for $\mathrm{pN}$ with D1 area, overall only 68 patients (3.2\%) had stage migration. In assessing the relationship between LN count and metastatic LN count in Fig. 1A, simply interpreting that in order for $\mathrm{LN}$ count to increase, metastatic $\mathrm{LN}$ count has to increase, with a corresponding increased potential for up-staging is not correct. LN count and metastatic LN count are not in a cause-and-effect relationship. Metastatic LN count is an indicator for the disseminating power of the primary tumor and is direct related to survival. As shown in Fig. 2, the LN positivity rate for the $\mathrm{LN} 8 \mathrm{a}, 9,11 \mathrm{p}$, and $12 \mathrm{a}$ areas was $0.7 \%$ for $\mathrm{pN} 0$ within the $\mathrm{D} 1$ area while the rate for $\mathrm{pN} 3 \mathrm{~b}$ within the $\mathrm{D} 1$ area increased to $83 \%$. Interestingly, this is almost the same as 1 - disease-specific cumulative survival rate, which could be explained based on the close relationship between the disseminating power of metastatic LN count and survival (Fig. 3). While there was no large difference in $\mathrm{pN} 0$ within $\mathrm{D} 1$, the upper $\mathrm{LN}$ count group showed low $\mathrm{LN}$ positivity from $\mathrm{pN} 1$ through $\mathrm{pN} 3$ within D1; the survival graph in Fig. 4 also showed the same trend in LN positivity rate. As suggested in previous reports on the significance of LN count, the reason for the low survival rate in the lower $\mathrm{LN}$ count group could be that the lower LN count is in a more distant area than that of the upper LN 

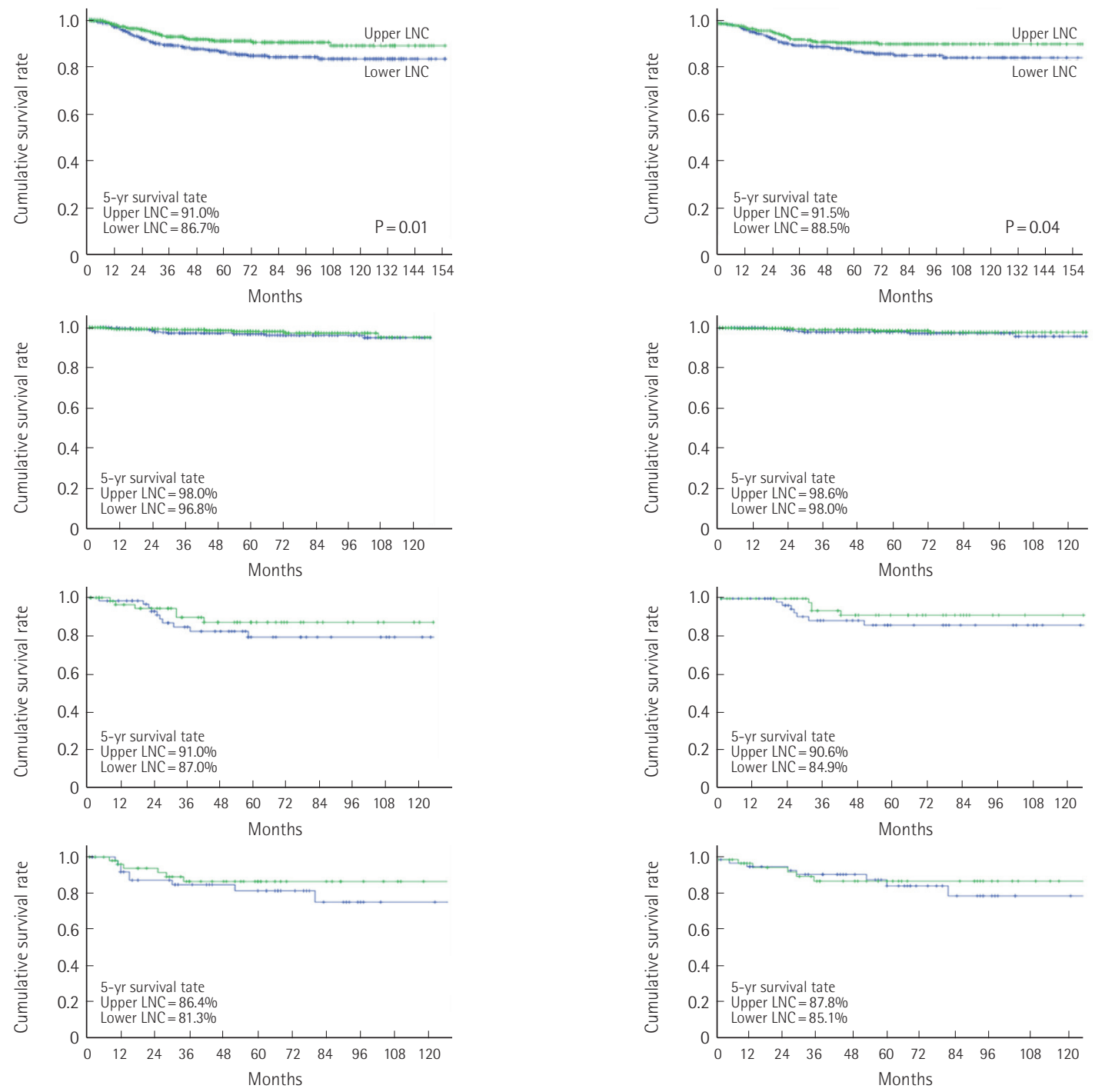

C
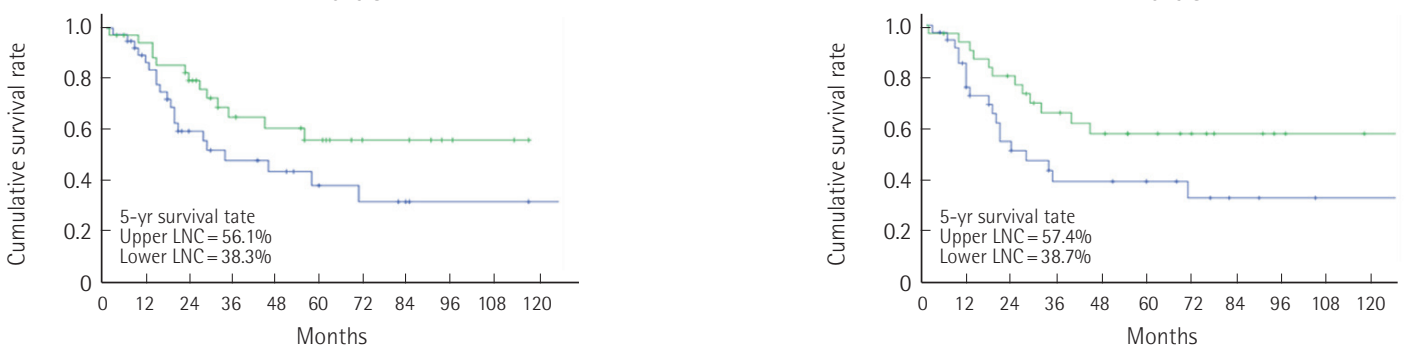

B

A

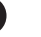


count, with more disseminated tumor cells rather than low quality surgery, resulting in missing positive LN caused by under-staging, The difference in survival between the lower and upper LN count groups in not only the D1 but also the D2 areas, as shown in Fig. 5, could be due to differences in dissemination in D2. From Fig. 1 we could hypothesize that metastatic LN count is an indicator of the disseminating power of the primary tumor and that the LN count is the indicator of the immunologic defense power of the host, which weakens the disseminating power. Also, these two trends are in proportion, in which cancer immunologic reaction causes local LN hyperplasia, resulting in larger LN size and higher detectability.

The role of LNs in cancer progression is still not fully understood. Multiple steps are necessary to successfully seed from tumor cells passing the lymphatic vessel to the draining LN that causes lymphatic metastasis, which is different from previous hypotheses. Therefore, successful LN metastasis requires that both tumor and host factors be fulfilled. The presence of a few LN metastases in solid tumors suggests that other clones from metastatic cells from the primary cancer site have escaped in large numbers. However, before the LN count can increase throughout the body, the LN count of the host may act as an immunologic defense barrier. There is no doubt that the immune system has an important role in patient prognosis. For example, tumor-infiltrating lymphocytes are linked to a favorable prognosis, in which the immune system plays an important role. However, to the authors' knowledge, few reports have shown a direct relationship between LN count and immunologic response. Kim et al. [10] and George et al. [11] recently reported tumor infiltration by lymphocytes and LN count to be related in colon cancer; in addition, while microsatellite instability is an immunologic factor and a well-known predictor for favorable prognosis in colon cancer, it has also been reported to be related to the LN count $[12,13]$.

While $\mathrm{LN}$ count and metastatic $\mathrm{LN}$ count are in proportion, the reason for differences between individuals and the direct parameter for immunologic response is unknown. Previous reports suggest that younger patients have higher LN counts, that Asians and non-Hispanic blacks have an increased frequency of higher LN count compared to that of non-Hispanic whites, and that patients diagnosed with higher stage and operated on have a higher LN count. The significant factors in our study included age under 60 years, low BMI, tumor size $>3 \mathrm{~cm}$, poorly-differentiated adenocarcinoma, diffuse-type Lauren classification, more extensive lymphadenectomy, and advanced $\mathrm{pT}$ and $\mathrm{pN}$ stage.

With low motivation during LN harvest along with inappropriate $\mathrm{LN}$ dissection, the possibility of stage migration due to missing positive $\mathrm{LN}$ does not disappear. In other cases, $\mathrm{LN}$ count does not need to be reflected in the patient's survival as an immunologic indicator [14]. However, as previous reports suggest, the LN ratio combined with LN count may better predict prognosis than UICC/AJCC $\mathrm{pN}$ stage. This is because the prediction accounts for stage migration; however, the results of the present study suggest that the host immune system may also play a role in the control of metastatic LN count, which is the disseminating force in tumor cells [8].

In conclusion, $\mathrm{LN}$ positivity and stage migration in the $\mathrm{D} 1$ and $\mathrm{D} 2 \mathrm{LN}$ dissection areas showed a trend for increasing $\mathrm{pN}$ stage; however, the overall trend was not statistically significant. The lower LN count group had a worse survival rate compared to that of the upper LN count group, suggesting that perigastric LN has an immunological defense role in weakening the disseminating power of metastatic tumor cells, as indicated by the LN count.

This study has some limitations. First, our long-term retrospective study design in a single Eastern institution could cause selection bias. Second, there may be treatment biases due to the progression of surgical skill, including LN dissection, and chemotherapy. Third, while cancer-related survival was the study end-point, the reported cause of death report was not always accurate.

\section{CONFLICT OF INTEREST}

No potential conflict of interest relevant to this article was reported.

\section{REFERENCES}

1. Edge SB, Compton CC. The American Joint Committee on Cancer: the 7th edition of the AJCC cancer staging manual and the future of TNM. Ann Surg Oncol 2010;17:1471-4.

2. Hanna GB, Amygdalos I, Ni M, Boshier PR, Mikhail S, Lloyd J, et al. Improving the standard of lymph node retrieval after gastric cancer surgery. Histopathology 2013;63:316-24.

3. Maduekwe UN, Lauwers GY, Fernandez-Del-Castillo C, Berger DL, Ferguson CM, Rattner DW, et al. New metastatic lymph node ratio system reduces stage migration in patients undergoing D1 lymphadenectomy for gastric adenocarcinoma. Ann Surg Oncol 2010;17:1267-77.

4. Pereira ER, Jones D, Jung K, Padera TP. The lymph node microenvironment and its role in the progression of metastatic cancer. Semin Cell Dev Biol 2015;38:98-105.

5. Liu HG, Liang H, Deng JY, Wang L, Liang YX, Jiao XG. The value of negative lymph node count in prediction of prognosis of advanced gastric cancer. Zhonghua Wai Ke Za Zhi 2013;51:66-70.

6. Biondi A, D’Ugo D, Cananzi FC, Papa V, Borasi A, Sicoli F, et al. Does a minimum number of 16 retrieved nodes affect survival in 
curatively resected gastric cancer? Eur J Surg Oncol 2015;41:77986.

7. Seevaratnam R, Bocicariu A, Cardoso R, Yohanathan L, Dixon M, Law $\mathrm{C}$, et al. How many lymph nodes should be assessed in patients with gastric cancer? A systematic review. Gastric Cancer 2012;15 Suppl 1:S70-88.

8. Morgan JW, Ji L, Friedman G, Senthil M, Dyke C, Lum SS. The role of the cancer center when using lymph node count as a quality measure for gastric cancer surgery. JAMA Surg 2015;150:37-43.

9. Degiuli M, Sasako M, Ponti A, Vendrame A, Tomatis M, Mazza C, et al. Randomized clinical trial comparing survival after D1 or D2 gastrectomy for gastric cancer. Br J Surg 2014;101:23-31.

10. Kim YW, Jan KM, Jung DH, Cho MY, Kim NK. Histological inflammatory cell infiltration is associated with the number of lymph nodes retrieved in colorectal cancer. Anticancer Res 2013;33:514350.

11. George S, Primrose J, Talbot R, Smith J, Mullee M, Bailey D, et al.
Will Rogers revisited: prospective observational study of survival of 3592 patients with colorectal cancer according to number of nodes examined by pathologists. Br J Cancer 2006;95:841-7.

12. Belt EJ, te Velde EA, Krijgsman O, Brosens RP, Tijssen M, van Essen $\mathrm{HF}$, et al. High lymph node yield is related to microsatellite instability in colon cancer. Ann Surg Oncol 2012;19:1222-30.

13. Mekenkamp LJ, van Krieken JH, Marijnen CA, van de Velde CJ, Nagtegaal ID; Pathology Review Committee and the Co-operative Clinical Investigators. Lymph node retrieval in rectal cancer is dependent on many factors: the role of the tumor, the patient, the surgeon, the radiotherapist, and the pathologist. Am J Surg Pathol 2009;33:1547-53.

14. Marchet A, Mocellin S, Ambrosi A, de Manzoni G, Di Leo A, Marrelli $\mathrm{D}$, et al. The prognostic value of $\mathrm{N}$-ratio in patients with gastric cancer: validation in a large, multicenter series. Eur J Surg Oncol 2008:34:159-65. 